\title{
Endovascular Treatment of a Ruptured Distal Anterior Cerebral Artery Aneurysm Using Coils and $\mathrm{N}$-Butyl-Cyanoacrylate in a 5-Month-Old Baby
}

\author{
Giancarlo Saal-Zapata1, Jesús Flores ${ }^{1} \quad$ Ricardo Vallejos $^{1}$ Dante Valer ${ }^{1}$ Walter Durand ${ }^{1}$ \\ Rodolfo Rodriguez ${ }^{1}$ \\ 1Department of Neurosurgery, Endovascular Neurosurgery Service,
Hospital Nacional Guillermo Almenara Irigoyen-EsSalud,
La Victoria, Lima, Peru

\begin{abstract}
Address for correspondence Giancarlo Saal-Zapata, MD, Department of Neurosurgery, Endovascular Neurosurgery Service, Hospital Nacional Guillermo Almenara Irigoyen-EsSalud, Grau Avenue 800, La Victoria, Lima 13, Peru, (e-mail: gian_carlo1987@hotmail.com; gsaal1987@gmail.com).
\end{abstract}

J Clin Interv Radiol ISVIR:2021;5:55-58

\begin{abstract}
Intracranial aneurysms in pediatric population are rare and differ in several features with their adult counterpart. Clipping and endovascular therapy have both demonstrated favorable clinical outcomes with reconstructive and deconstructive techniques. We present the case of a 5-month-old infant who was admitted to the emergency with interhemispheric and syl-

Keywords

- aneurysm

- pediatric aneurysm

- glue

- coils

- N-butyl-cyanoacrylate vian subarachnoid hemorrhage. CT angiography and three-dimensional digital subtraction angiography revealed a ruptured left pericallosal aneurysm with morphological features of a dissecting aneurysm. Coiling and $\mathrm{N}$-butyl-cyanoacrylate administration were employed to occlude the aneurysm without complications. Endovascular therapy is an effective and safe option in cases of ruptured intracranial aneurysms in pediatric patients with favorable clinical and radiological outcomes.
\end{abstract}

\section{Introduction}

Intracranial aneurysms in the pediatric population are rare and represent 0.5 to $4.6 \%$ of all aneurysms. ${ }^{1}$ Male predominance, location in posterior circulation, traumatic etiology, dissecting/fusiform morphology, and giant size are some features of these lesions in children. ${ }^{2-6}$ Noninvasive diagnostic tools such as computed tomographic angiography (CTA) and magnetic resonance angiography are routinely used to assess the morphology and etiology of these lesions. However, digital subtraction angiography (DSA) still remains as the gold standard procedure. ${ }^{7}$ Clipping and endovascular therapy (EVT) are the available options for treatment and both techniques aim to exclude the aneurysm from the circulation using reconstructive and deconstructive techniques. ${ }^{7-10}$ Nevertheless, in many cases parent vessel occlusion (PVO) has to be performed due to the characteristics of the aneurysm.
Endovascular techniques have been employed in the treatment of pediatric aneurysms such as coiling, glue embolization, and stent placement. ${ }^{9,11,12}$ Nevertheless, a combined approach using coils with a liquid embolic agent is infrequently reported in the literature.

Thus, we present a case of a 5-month-old infant with a ruptured distal anterior cerebral artery aneurysm treated successfully with coils and $\mathrm{N}$-butyl-cyanoacrylate (NBCA).

\section{Case Report}

A 5-month-old infant without relevant past medical history presented to the emergency with 2 days of irritability, lethargy, and vomiting. A brain CT scan revealed a Fisher 3 interhemispheric and sylvian subarachnoid hemorrhage ( -Fig. 1A). A three-dimensional CTA showed a dissecting
DOI https://doi.org/ $10.1055 / \mathrm{s}-0040-1715027$ ISSN 2457-0214. (c) 2021. Indian Society of Vascular and Interventional Radiology. This is an open access article published by Thieme under the terms of the Creative Commons Attribution-NonDerivative-NonCommercial-License, permitting copying and reproduction so long as the original work is given appropriate credit. Contents may not be used for commercial purposes, or adapted, remixed, transformed or built upon. (https://creativecommons.org/licenses/by-nc-nd/4.0/).

Thieme Medical and Scientific Publishers Pvt. Ltd. A-12, 2nd Floor, Sector 2, Noida-201301 UP, India 

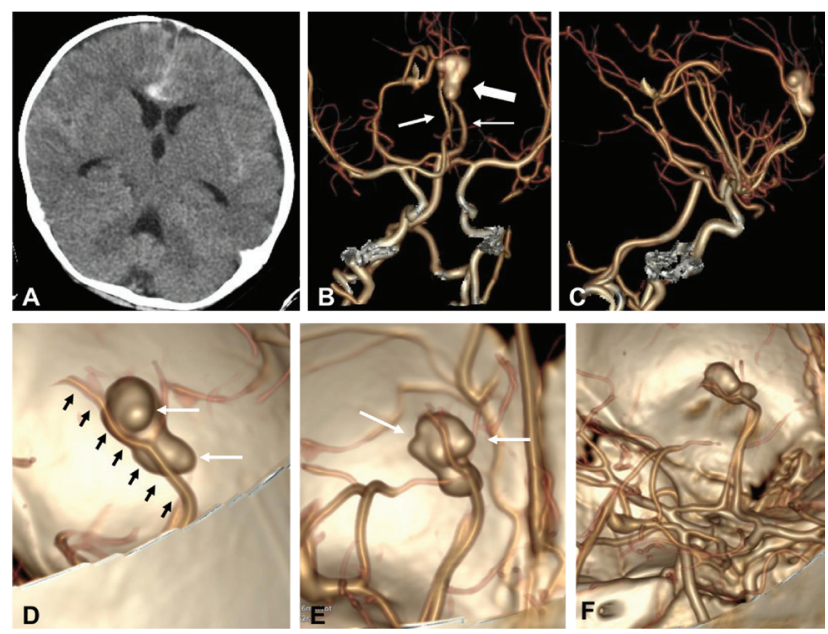

Fig. 1 (A) Brain CT scan showing interhemispheric and sylvian subarachnoid hemorrhage. (B) 3D-CTA in frontal view shows both anterior cerebral arteries (thin arrows) and the aneurysm arising from the left ACA (thick arrow). (C) 3D-CTA in lateral view shows normal trajectory of right ACA. (D-F) Magnification of CTA reveals the close relationship of the right ACA with the aneurysm (black arrows), the presence of blebs (white arrows), and the absence of blood flow filling distal to the left ACA. 3D, three-dimensional; ACA, anterior cerebral artery; CTA, computed tomographic angiography.

aneurysm in the left pericallosal artery. Blebs and close relationship with the right anterior cerebral artery (ACA) were also found (-Fig. 1B-F).

Endovascular treatment was proposed and under general anesthesia, a 4-French sheath was inserted in the right femoral artery by Seldinger technique using manual palpation. Thereafter, a 4,2-French Fargo Mini (Balt) guide catheter was navigated under fluoroscopy and the diagnostic angiogram showed a left A3 aneurysm (-Fig. 2A, B) with poor supply from the ipsilateral pericallosal artery distal to the aneurysm. Moreover, the left vertebral artery showed retrograde supply by the posterior splenic artery. The three-dimensional-DSA revealed a $13.7 \mathrm{~mm} \times 4.6 \mathrm{~mm}$ aneurysm with irregular shape, the presence of blebs, and a postaneurysmal narrowing, all these findings corresponded to a dissecting aneurysm ( - Fig. 2E, F). Under road mapping the Headway Duo $167 \mathrm{~cm}$ (Microvention Terumo) over a Traxcess 14 (Microvention Terumo) microwire was navigated through the left ACA to the aneurysm ( - Fig. 2C). A superselective angiogram was performed to confirm the position of the microcatheter ( $\mathbf{- F i g}$. $\mathbf{2 G}$ ). Once in the sac, four coils were delivered without complications achieving an adequate packing density ( - Fig. 2D). Thereafter, $0.2 \mathrm{~mL}$ of NBCA was administered achieving a complete occlusion of the aneurysm and the parent artery ( $\mathbf{- F i g}$. $\mathbf{2 H}$ ). The immediate postembolization angiogram showed a Raymond Roy I occlusion ( - Fig. 3A, B) with PVO ( - Fig. 3C, D). An angiogram of the left vertebral artery confirmed the patency from the posterior pericallosal artery that supplied the territory of the left pericallosal artery previously occluded with glue ( - Fig. $3 E, F)$. In the postoperative course the patient presented seizures that were controlled with medication. The 1-day postoperative brain CT did not show any alterations and the 4-day CT showed an infarct in the territory of the left ACA without mass effect or brain
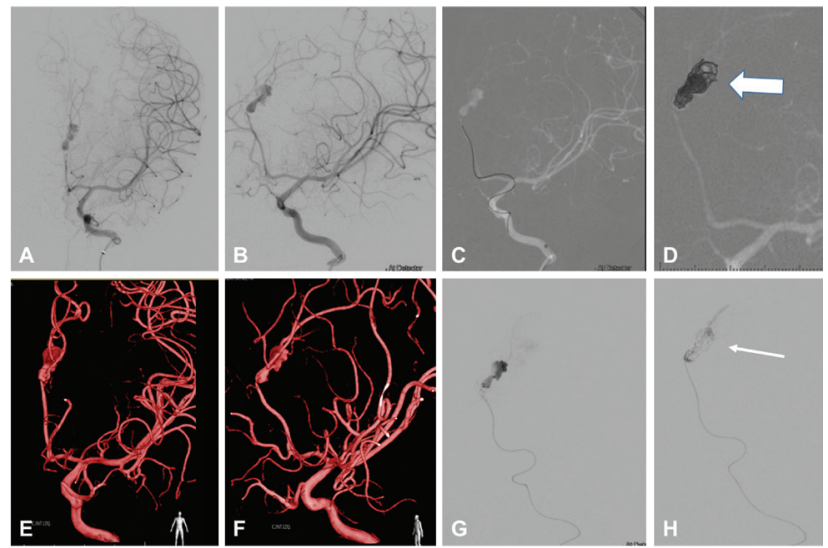

Fig. 2 (A,B,E,F) DSA with 3D reconstruction in frontal and oblique views showing the $A 3$ aneurysm arising from the left anterior cerebral artery. (C,G) Road mapping shows navigation of the Headway Duo microcatheter over the Traxcess 14 microwire and the superselective injection. (D) Road mapping shows the presence of coils (thick arrow) and adequate packing of the aneurysm. (H) After coiling, $0.2 \mathrm{~mL}$ of NBCA (thick arrow) was administered to seal the aneurysm and the artery. DSA, digital subtraction angiography; NBCA, $\mathrm{N}$-butyl-cyanoacrylate.
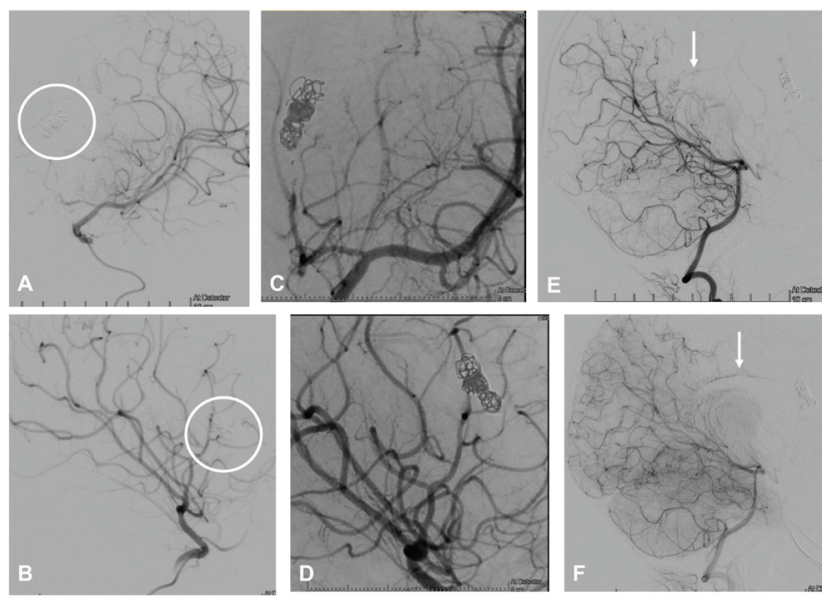

Fig. 3 (A, B) DSA after embolization with coils and NBCA show complete obliteration of the aneurysm (circle). (C, D) Fluoroscopy shows the presence of coils. (E, F) DSA of the posterior circulation in lateral view shows filling of the pericallosal artery through a patent posterior pericallosal artery (arrow) arising from the posterior cerebral artery. DSA, digital subtraction angiography; NBCA, N-butyl-cyanoacrylate.
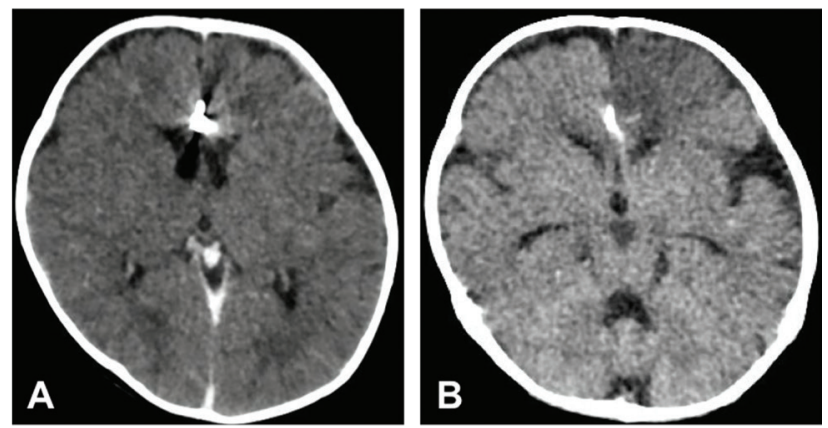

Fig. 4 (A) Immediate postoperative brain CT shows the presence of coils. (B) Four days after the intervention, CT shows an infarct in the anterior cerebral artery territory without mass effect. CT, computed tomography. 
compression (-Fig. 4). The patient was discharged home with seizure-related medication and without deficits.

\section{Discussion}

Intracranial aneurysms in childhood are rare. This pathology has different features when compared with the adult population in terms of epidemiology, clinical presentation, aneurysm characteristics, treatment, and outcomes.

Male predominance is a common finding in the majority of the series, with a female increasing incidence when the child is older.8 This relation inverts in the second decade of life. Regarding the morphology of the aneurysms, fusiform and dissecting aneurysms are more frequently found in children under 10 years, whereas saccular aneurysms are more common in children older than 10 years of age. ${ }^{4,6,8}$ For instance, Hetts et al evaluated 77 patients with a mean age of 12 years where female and saccular aneurysms were more frequent. ${ }^{8}$ Distally located aneurysms, pseudoaneurysm presence, traumatic origin, spontaneous thrombosis, ${ }^{13,14}$ seizures and giant aneurysms are also characteristics in this population. ${ }^{2,3}$

Despite fusiform aneurysms are frequently found in patients in the first decade of life, ${ }^{4}$ in the great majority of these cases the etiology is unknown, ranging from 65 to $90 \% .1,4,7,-9,15$ On the other hand, saccular aneurysms are rare and only eight cases have been treated by embolization in patients under 30-month-old with good results. ${ }^{16}$ EVT cases have been performed during the first 2 months of life in only two cases. ${ }^{17}$ Regarding their location, the internal carotid artery bifurcation followed by middle cerebral artery is the more common site in the anterior circulation.

Compared with adults, the incidence of posterior circulation aneurysms is higher (29.7\%), ${ }^{15}$ the incidence of multiple aneurysms is lower (12 vs. $30 \%$ ), and the most frequent presentation is subarachnoid hemorrhage.

Lasjaunias in his series intends to explain the possible mechanisms for aneurysm development hypothesizing that wall vessel dysfunctions triggered their formation, including infections, mutations, and genetic defects. ${ }^{5}$

The annual recurrence rate according to the series of Kakarla et al is $2.6 \%,{ }^{10}$ and the incidence of de novo aneurysms formation is around $8 \%{ }^{10,18,19}$ At long-term follow-up, 6 out of 114 pediatric patients presented de novo aneurysms in a finish study, representing $5 \%$ of this population. The majority of the patients were treated surgically. ${ }^{18}$ In neonates, the most common treatment modality was clipping with microsurgical vessel ligation, whereas EVT was performed in six patients. ${ }^{20}$

Three papers reported treatment of pediatric aneurysms by endovascular means only and they showed similar results: a higher proportion of giant aneurysms and fusiform aneurysms were most frequently found with parent vessel sacrifice as the most common technique used in these cases, the mean follow-up period ranged from 23.5 months to 3 years and favorable outcomes ranged from 87 to $96 \% .^{9,11,12}$ Moreover, a recent meta-analysis stated that endovascular treatment and surgery yielded comparable rates of favorable outcomes in rupture and unruptured aneurysms.?

With this evidence, EVT remains as the first-line treatment in cases of ruptured and unruptured pediatric aneurysms using reconstructive and deconstructive techniques. In addition, long-term follow-up is recommended if EVT is chosen, to assess for recanalization and de novo aneurysms formation. $8.10,18,19$

PVO is the treatment of choice in cases of fusiform or dissecting aneurysms according to the previous published papers. A previous angiographic evaluation to assess collateral circulation and leptomeningeal anastomosis is mandatory before this technique is employed.

Aneurysms in babies younger than 1 year of age are very rare and they pose a challenge to catheterize the femoral artery and to decide the appropriate treatment due to their complex configuration. A similar case in a 2-month-old baby with an A3 ruptured aneurysm was treated by clipping with good results. ${ }^{21}$

We chose EVT because embolization is the first-line treatment at our institution and results from case-series have demonstrated favorable clinical outcomes when compared with surgery including reconstructive and deconstructive techniques. ${ }^{7-9,11,12,15,22,23}$ Age and the accessibility to navigate through the vessels were also considered in this case. The morphology of this aneurysm was based on angiographic features: the presence of postaneurysmatic parent artery narrowing, irregular shape, and lack of distal supply are suggestive of a fusiform/dissecting aneurysm. No traumatic, infectious, or congenital antecedents were found and we considered the etiology of this aneurysm unknown.

Endovascular treatment aims to occlude the aneurysm sac and neck and in some cases depending on the etiology or morphology PVO with coils or embolic substances is the best alternative. Currently, the endovascular techniques employed are coiling, stent-assisted coiling, glue embolization, combination of the previous and selected cases, placement of flow diverter devices. ${ }^{24}$ Nevertheless, the combination of coiling and liquid embolic agents (Onyx, Medtronic) has been reported only in one case with complete obliteration. ${ }^{25}$

In our case, to achieve a complete obliteration and to avoid recanalization of the aneurysm we decided to administer NBCA into the aneurysm sac and parent artery after coiling. The limitation of this case is that the patient was lost for follow-up. Nevertheless, due to the rarity of these aneurysms at this age, we considered this treatment the most feasible and less invasive.

\section{Conclusion}

Endovascular treatment is a feasible option in cases of ruptured aneurysms in the pediatric population, including reconstructive and reconstructive techniques.

\section{Conflict of Interest}

None declared. 


\section{References}

1 Huang J, McGirt MJ, Gailloud P, Tamargo RJ. Intracranial aneurysms in the pediatric population: case series and literature review. Surg Neurol 2005;63(5):424-432, discussion 432-433

2 Chen R, Zhang S, Guo R, You C, Ma L. Pediatric intracranial pseudoaneurysms: a report of 15 cases and review of the literature. World Neurosurg 2018;116:e951-e959

3 Chen R, Zhang S, Guo R, Ma L, You C. Pediatric intracranial distal arterial aneurysms: report of 35 cases. Acta Neurochir (Wien) 2018;160(8):1633-1642

4 Gross BA, Smith ER, Scott RM, Orbach DB. Intracranial aneurysms in the youngest patients: characteristics and treatment challenges. Pediatr Neurosurg 2015;50(1):18-25

5 Lasjaunias PL, Campi A, Rodesch G, Alvarez H, Kanaan I, Taylor W. Aneurysmal disease in children. Review of 20 cases with intracranial arterial localisations. Interv Neuroradiol 1997;3(3):215-229

6 Lasjaunias P, Wuppalapati S, Alvarez H, Rodesch G, Ozanne A. Intracranial aneurysms in children aged under 15 years: review of 59 consecutive children with 75 aneurysms. Childs Nerv Syst 2005;21(6):437-450

7 Yasin JT, Wallace AN, Madaelil TP, et al. Treatment of pediatric intracranial aneurysms: case series and meta-analysis. J Neurointerv Surg 2019;11(3):257-264

8 Hetts SW, Narvid J, Sanai N, et al. Intracranial aneurysms in childhood: 27-year single-institution experience. AJNR Am J Neuroradiol 2009;30(7):1315-1324

9 Takemoto K, Tateshima S, Golshan A, et al. Endovascular treatment of pediatric intracranial aneurysms: a retrospective study of 35 aneurysms. J Neurointerv Surg 2014;6(6):432-438

10 Kakarla UK, Beres EJ, Ponce FA, et al. Microsurgical treatment of pediatric intracranial aneurysms: long-term angiographic and clinical outcomes. Neurosurgery 2010;67(2):237-249, discussion 250

11 Lv X, Jiang C, Li Y, Yang X, Wu Z. Endovascular treatment for pediatric intracranial aneurysms. Neuroradiology 2009; 51(11):749-754

12 Saraf R, Shrivastava M, Siddhartha W, Limaye U. Intracranial pediatric aneurysms: endovascular treatment and its outcome. J Neurosurg Pediatr 2012;10(3):230-240

13 Kasliwal MK, Suri A, Sai Kiran NA, Sharma BS. Spontaneous thrombosis of giant cavernous internal carotid artery aneurysm in a neonate. Case report and review of the literature. Pediatr Neurosurg 2008;44(4):329-332
14 Sabanci PA, Aras Y, Aydoseli A, et al. A thrombosing, giant, distal posterior cerebral artery aneurysm in a newborn infant. J Neurosurg Pediatr 2012;10(1):50-55

15 Agid R, Souza MPS, Reintamm G, Armstrong D, Dirks P, TerBrugge KG. The role of endovascular treatment for pediatric aneurysms. Childs Nerv Syst 2005;21(12):1030-1036

16 Lyon KA, Arrey EN, Haider AS, Jeevan DS, Benardete EA. Endovascular treatment of a large ruptured middle cerebral artery bifurcation aneurysm in a 5-week-old infant: case report. J Neurosurg Pediatr 2017;20(4):357-363

17 Rana AK, Koumellis P, Jaspan T, Cartmill M, McConachie NS. Coil embolization of ruptured middle cerebral artery aneurysms in the first 2 months of life. Report of two cases. J Neurosurg 2007;107(suppl 3) :232-235

18 Koroknay-Pál P, Lehto $H$, Niemelä $M$, Kivisaari $R$, Hernesniemi J. Long-term outcome of 114 children with cerebral aneurysms. J Neurosurg Pediatr 2012;9(6):636-645

19 Mitchell B, Dash D, Humphries W, Mawad M. De novo intracranial aneurysm formation following endovascular treatment of giant aneurysm in an infant: case report. Childs Nerv Syst 2012;28(4):645-648

20 Mohotti JE, Carter NS, Zhang VJW, et al. Neonatal intracranial aneurysms: case report and review of the literature. J Neurosurg Pediatr 2018;21(5):471-477

21 Fathi NQ Syahrilfazli AJ, Azizi AB, Redzuan IM, Sobri M, Kumar R. Ruptured giant left distal anterior cerebral artery aneurysm in a two-month-old baby. Pediatr Neurosurg 2015;50(5):275-280

22 Stiefel MF, Heuer GG, Basil AK, et al. Endovascular and surgical treatment of ruptured cerebral aneurysms in pediatric patients. Neurosurgery 2008;63(5):859-865, discussion 865-866

23 Liang J, Bao Y, Zhang H, et al. The clinical features and treatment of pediatric intracranial aneurysm. Childs Nerv Syst 2009;25(3):317-324

24 Colby GP, Jiang B, Bender MT, et al. Pipeline-assisted coil embolization of a large middle cerebral artery pseudoaneurysm in a 9-month-old infant: experience from the youngest flow diversion case. J Neurosurg Pediatr 2018;22(5):532-540

25 Ghali MGZ, Srinivasan VM, Cherian J, et al. Multimodal treatment of intracranial aneurysms in children: clinical case series and review of the literature. World Neurosurg 2018; 111:e294-e307 